$$
\Rightarrow
$$




\section{A ASCENSÃO DAS MARCAS SOLIDÁRIAS}

| POR BENJAMIN ROSENTHAL

\section{Marcas solidárias fabricaram e doaram itens essenciais para o combate à Covid-19, ganhando repercussão nas redes sociais. $O$ contexto da crise vai passar, mas será que a solidariedade permanecerá?}

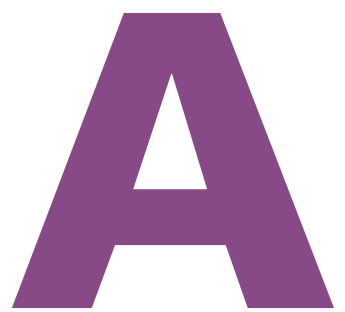

pandemia da Covid-19 tornou-se o centro da vida cotidiana. Pesquisa feita pela empresa de tecnologia de monitoramento social Stilingue intitulada Vozes da pandemia mostra que as conversas em redes sociais ao redor do coronavírus envolvem palavras como "quarentena", "isolamento social", "cloroquina”, "curva", "médicos", "China”, "EUA", "mortes", "ciência" e "testes". São palavras que sugerem preocupação com o problema, com as formas de resolvê-lo ou minimizá-lo e com o que se passa no mundo. Aparecem, ainda, palavras como "lives" e "Deus", o que revela que tanto o lazer quanto a fé também são elementos importantes. Diante do contexto de grande preocupação que traz a Covid-19, o que as marcas podem comunicar? Como podem entrar ou se conectar com conversas em andamento entre os diversos públicos?

A escuta ativa nas redes sociais é parte das atividades dos departamentos de marketing. A escolha de conteúdo deve passar pela decisão de introjetar conversas existentes ou de seguir uma direção própria. No contexto da pandemia, ignorar os interesses e as interações em voga parece ser uma má aposta. Marcas com ações que dialogam com as con- versas ao redor da pandemia têm maiores chances de expandir sua visibilidade nas redes sociais.

Isso porque as marcas ganham a atenção das pessoas quando suas intervenções conseguem refletir, reforçar ou reconfigurar os significados que estão presentes na sociedade. Pesquisadores em cultura de consumo chamam isso de ressonância da marca (como bem descrito em trabalhos de Craig Thompson e Douglas Holt, entre outros). Susan Fournier, Michael Solomon e Basil Englis escreveram sobre o tema em When brands resonate, capítulo do Handbook on Brand and Experience Management. A força de uma marca vem de conteúdos que ressoam nos níveis individual (no fit da marca com a vida pessoal), cultural (no fit entre marca e valores coletivos) e organizacional (no fit entre marca e colaboradores). Em todos esses níveis, hoje a pandemia é a temática dominante, e as pessoas esperam que as marcas se envolvam com o combate à Covid-19, conforme mostra, por exemplo, pesquisa realizada pelo Twitter (veja no gráfico).

\section{O MOMENTO}

Percebe-se que as grandes marcas caminham em uma direção que eu denomino de marcas solidárias, com uma repercussão bastante positiva, o que contribui para a reputação, 


\section{O QUE OS USUÁRIOS DO TWITTER ESPERAM QUE AS MARCAS FAÇAM DURANTE A COVID-19 (\% DOS RESPONDENTES)*}

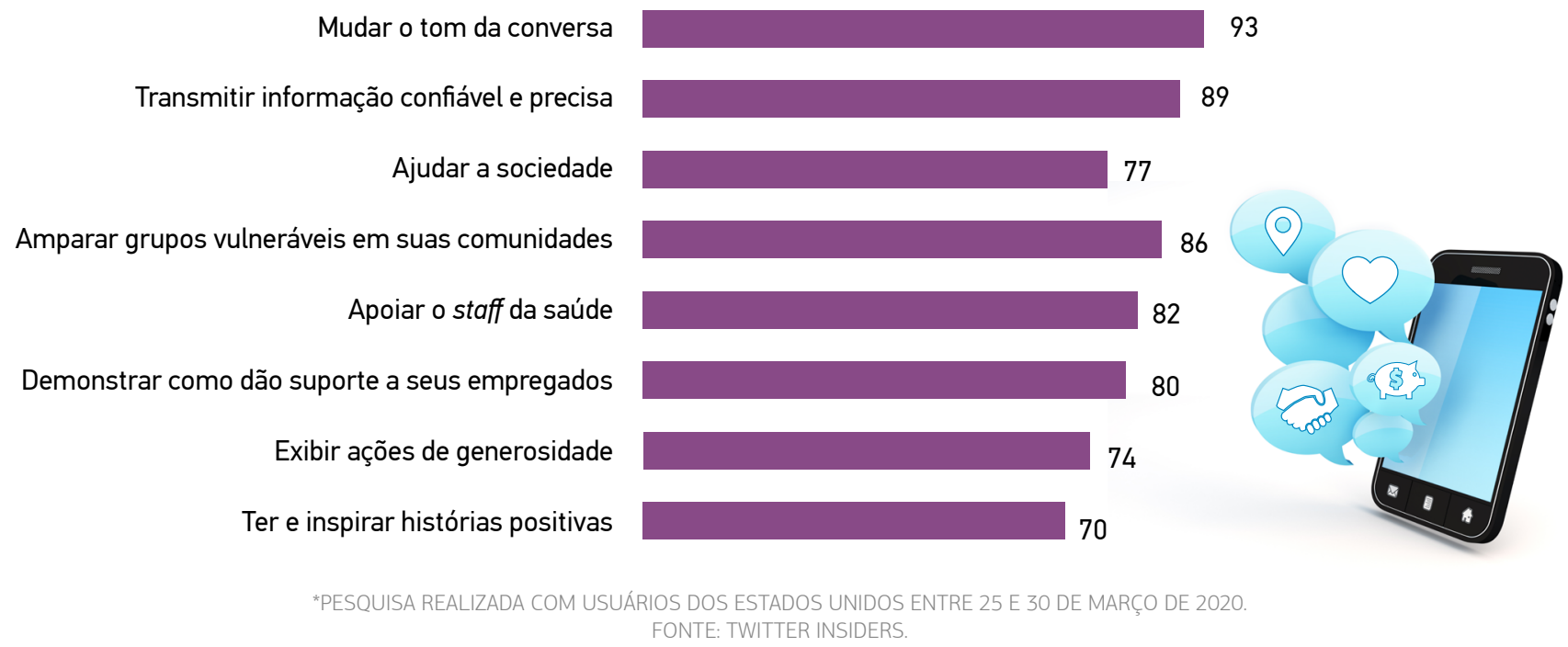

a força e o valor dessas marcas. A esses objetivos tradicionais de qualquer marca, adicionam-se outros: promover o bem-estar e a felicidade coletiva.

Alguns exemplos de ações solidárias (de marcas e organizações) são a produção e doação de álcool gel para hospitais (Ambev, Natura, Raízen e L'Oréal), a fabricação de máscaras de proteção para profissionais de saúde (DeMillus, Grupo Reserva e Vila Romana), a doação de produtos de higiene para populações vulneráveis (Natura, O Boticário, Minuano, P\&G e Grupo Hinode) e o movimento Não Demita, que até o dia 19 de abril já contava com a adesão de mais de 3.300 empresas, entre elas (e eu lamento não ter espaço para citar todas) Accenture, Alpargatas, Bradesco, $\mathrm{O}$ Boticário, Itaú Unibanco, Magazine Luiza, Natura e Renner. É importante mencionar ainda a doação de recursos financeiros, como as realizadas por acionistas do Magazine Luiza e Itaú Unibanco (entre muitos outros).

A empresa de pesquisa digital MindMiners perguntou aos consumidores sobre marcas com ações no período da Covid-19. As mais lembradas foram Ambev, Bradesco, Itaú Unibanco, Santander, Magazine Luiza, Natura, Ypê, Nestlé, Riachuelo, O Boticário, Cacau Show e Banco do Brasil, todas elas de fato promovendo ações solidárias. Isso indica que o consumidor percebeu essas ações, inclusive por terem sido coletivas e concentradas no tempo, o que aumentou o impacto.

\section{A velha publicidade está moribunda, sustentada por aparelhos. Marcas solidárias são um dos caminhos para uma nova publicidade.}

A marca solidária é um tipo de marca ativista, conceito que na área de cultura de consumo é associado ao protagonismo em endereçar questões éticas e de interesse social. No passado, a marca ativista tentava passar desinteresse econômico, o que sinalizava autenticidade, mas, uma vez que todos sabem que marcas têm interesses comerciais, a estratégia mudou para mostrar o valor que entregam, conforme argumenta Douglas Holt, no artigo seminal Why do brands cause trouble? A dialectical theory of consumer culture and branding.

A marca ativista é um fenômeno crescente e que se deu na mesma medida em que o consumerismo político cresceu - o consumo motivado por questões éticas, como bem elaborado na obra da professora e pesquisadora Michele Mi- 


\section{O contexto de pandemia vai passar. Assim, é importante olhar para o zeitgeist, que pede mais atuação das marcas sobre causas sociais.}

cheletti, da Stockholm University. A marca solidária pratica ativismo social, mas não necessariamente adota uma postura ativista, esta sim um posicionamento perene. A solidariedade pode ser um momento breve na vida da marca. No atual contexto, muitas das marcas que adotam uma atitude solidária parecem ter motivações de ordem circunstancial; não necessariamente é algo que pertence ao seu posicionamento.

No contexto da Covid-19, as marcas solidárias também parecem agir em grupo. Gestores procuram seguir modelos que admiram, em processos conhecidos no meio acadêmico como mimetização - quem quiser saber mais sobre como ocorre esse tipo de processo deve conferir no artigo Mimicry: causes and consequences, de Korrina Duffy e Tanya Chartrand, publicado no periódico Current Opinion in Behavioral Sciences em 2015. Possivelmente, no caso das ações das marcas em meio à pandemia, a inspiração dos pioneiros foi um elemento importante, catapultado pela visibilidade conferida em redes hiperconectadas, levando a que outros fizessem rapidamente o mesmo.

A sequência de empresas que anunciaram suas ações de solidariedade no combate à Covid-19 foi frenética. Em um espaço de poucos dias todas as marcas citadas neste artigo anunciaram suas contribuições. Havia um senso de urgência que o contexto fomentava. As pioneiras acabam, indiretamente, provocando outras a seguirem pelo mesmo caminho em suas estratégias de comunicação. Se o que uma marca faz de mais relevante em dado momento é ser solidária, por que não inspirar outras a fazer o mesmo?

\section{O FUTURO}

Questão de ordem estratégica: o que ficará de residual nisso tudo? A atitude de uma marca solidária será apenas momentânea, como reflexo da pandemia? Ou veremos mudanças estruturais no papel das marcas, em como enxergam que podem e devem contribuir? É algo para ser observado. É importante entender ações de marcas por uma perspectiva contextual, e o contexto de pandemia vai passar. Mas também é importante olhar para o zeitgeist e este pede mais atuação das marcas sobre causas sociais. A Covid-19 pode ter a função de gatilho na aceleração da mudança.

A solidariedade é um conceito humanista que conecta os indivíduos, quem sofre e quem vê sofrer, ricos e pobres, fortes e fracos; é um princípio que inspira e guia a ação, para além da mera emoção, rumo ao interesse comum, que são a grandeza e a dignidade do homem, como bem definiu Hannah Arendt no livro On revolution. A solidariedade pode se conectar a uma causa, a ser defendida em questões de gênero, liberdade sexual, estabilidade no emprego, saúde mental, combate ao idadismo, entre outras, mas a solidariedade, como princípio norteador, vem antes de qualquer causa.

No mundo pré-Covid-19, as pessoas notavam a predominância do individualismo e a ausência de confiança nas relações cotidianas, como demonstrado em pesquisa realizada pelo Pew Research Center, nos Estados Unidos. Por outro lado, as mesmas pessoas desejam que não seja dessa forma. Demonstrações de solidariedade são fartas nas redes sociais em tempos de Covid-19, mas redes sociais são espaços nos quais a sinalização de virtude é um forte motivador. Ainda assim, existe uma pressão crescente sobre organizações por um maior engajamento e responsabilidade social, além de certa premiação pública (e maior visibilidade) a marcas que entregam ações na direção da solidariedade.

Eu não arrisco dizer que o mundo se tornará mais solidário no pós-Covid-19 (ainda que eu deseje isso). Esse tipo de previsão está além das minhas capacidades, mas arrisco dizer que existem incentivos para que as marcas se tornem mais solidárias.

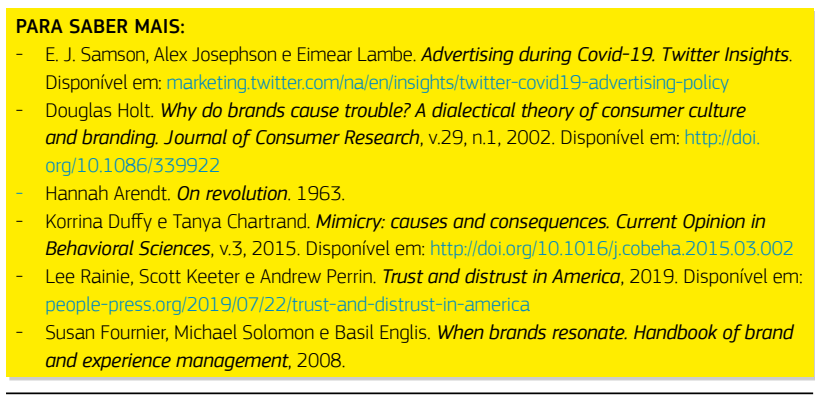

BENJAMIN ROSENTHAL > Professor da FGV EAESP > benjamin.rosenthal@fgv.br 